\title{
IbM BIODIVERSIFIKASI ENERGI ALTERNATIF LIMBAH KELAPA SAWIT DAN JAGUNG DI DESA SUMBER MAKMUR KABUPATEN MUKOMUKO
}

\section{IbM BIODIVERSIFICATION OF ALTERNATIVE ENERGY WASTE OF PALM OIL AND CORN IN SUMBER MAKMUR MUKOMUKO}

\author{
Oleh: \\ ${ }^{I}$ Devi Ratnawati, ${ }^{2}$ Charles Banon \\ Chemistry Department, University of Bengkulu, Bengkulu, Indonesia \\ Email:devi_r64@yahoo.com
}

\begin{abstract}
The purpose of the program IbM are: (a) improving the knowledge and skills of the public about waste palm oil and corn into alternative energy approach to science and technology applied, (b) train waste processing palm oil and corn as an energy, (c) accompanying ways of processing, manufacturing and marketing of oil and corn waste products on an industrial scale household. The method of implementation used action research includes four stages, namely: program planning, execution, observation and evaluation, and reflection. In planning the activities conducted debriefing, the socialization of the target audience and the preparation of training programs. On the implementation of the program, carried out the implementation of program activities that include improvement of knowledge and skills, demonstrations and coaching as well as technology training applied sewage treatment production of palm oil and corn for processing into biogas, briquettes, organic fertilizers and various handicrafts of high economic value. The evaluation was done to see the extent to which program activities have been implemented, while the reflection conducted to determine the deficiency or excess of the activities that have been carried out in order to establish recommendations for the survival or development of subsequent activities. From some of the activities that have been done, the community was very enthusiastic in participating in these activities, especially the installation of a simple biogas filling material made from oil palm empty fruit bunches and cow dung. The main constraints of this activity is the difficulty of marketing the craft because the economic condition of the majority of people of middle so that they concentrate on fulfilling their basic needs.
\end{abstract}

Keywords: palm oil, corn waste, biogas, biodiversification

\section{PENDAHULUAN}

Desa Sumber Makmur Kabupaten muko-muko berjarak sekitar 725 KM dari ibukota Provinsi Bengkulu. Daerah ini dikenal sebagai salah satu daerah penghasil kelapa sawit dan jagung terbesar di Bengkulu, sebanyak luas lahan perkebunan mencapai $110.000 \mathrm{Ha}$ (BPS, 2013). Setiap tahunnya dihasilkan 84.872 ton sawit dan 26.332 ton jagung pipilan kering dengan 67.000 ton/tahun limbah bahan organik perkebunan berupa tandan kosong kelapa sawit (TKKS), cangkang, serta kulit, bonggol dan batang jagung. 
Lokasi desa-desa yang ada di kabupaten Muko-muko sebagian besar terletak di daerah pedalaman sehingga kegiatan Pengabdian Pada Masyarakat (P2M) di bidang IPTEKS terapan yang dilakukan oleh Universitas Bengkulu ataupun Perguruan Tinggi lainnya sangat jarang sampai ke wilayah-wilayah tersebut. Hal ini mengakibatkan masyarakat jarang terlibat dalam kegiatan-kegiatan ilmiah yang dilakukan oleh Perguruan Tinggi, sebagai dampaknya pengetahuan dan pemahaman para masyarakat di wilayah ini masih kurang terkait dengan pengolahan limbah organik sebagai energi alternatif dan kegiatan IPTEKS lainnya.

Jauhnya jarak desa ini dari kota disekitarnya menyebabkan pemenuhan kebutuhan masyarakat terkendala oleh jarak dan transportasi. Selama ini kebutuhan masyarakat kabupaten tersebut dipasok dari Bengkulu dan Padang menggunakan jalur darat, dikarenakan jarak tempuh yang sangat jauh menyebabkan harga jual kebutuhan menjadi sangat mahal. Diantara kebutuhan yang sangat penting adalah bahan bakar gas dan pupuk subsidi, belum beroperasinya dermaga di wilayah tersebut mengakibatkan pasokan dikirim melalui jalur darat sehingga dengan kondisi jalan yang sangat buruk membuat harga melonjak lebih dari 30\% dari harga normal.

Dengan adanya penghapusan subsidi untuk BBM dan pupuk, membuat kehidupan masyarakat di daerah ini menjadi semakin sulit. Bahan bakar gas untuk keperluan rumah tangga sangat sulit di dapat, apalagi setelah pengapusan subsidi untuk bahan bakar gas, harga LPG setiap bulan terus merangkak naik menyesuaikan fluktuasi harga minyak dunia. Banyak warga yang beralih menggunakan kayu bakar untuk memasak dengan memanfaatkan pelepah sawit ataupun Tandan Kosong Kelapa Sawit (TKKS) dan cangkang sisa penggilingan sawit yang dibuang berserakan oleh 6 pabrik pengolahan kelapa sawit. Dikarenakan jumlahnya sangat banyak dan semakin menumpuk, maka menjadi limbah yang menimbukan bau sangat tidak sedap dan mengganggu keindahan lingkungan. Sama halnya dengan petani jagung, mereka hanya menumpuk limbah material organik hasil panennya yang berupa, bonggol, kulit (klobot) dan batang jagung. Setelah limbah organik ditumpuk lebih dari 1 bulan maka akan timbul bau tak sedap akibat produksi gas metana $\left(\mathrm{CH}_{4}\right)$ dan $\mathrm{CO}_{2}$, gas ini dapat digunakan sebagai alternatif bahan bakar gas, namun jika terlepas ke udara dapat menyebabkan peningkatan efek rumah kaca.

Penghentian subsidi pupuk juga berdampak buruk bagi daerah ini, sejak diberlakukan kebijakan tersebut maka saat ini daerah tersebut kekurangan 15ribu ton pupuk setiap tahunnya untuk memenuhi kebutuhan lahan perkebunan mereka yang sangat luas (Pecawan, 2015). Hanya 30\% jumlah pupuk yang dipenuhi oleh pemerintah, sisanya mereka mengambil dari provinsi lain dengan harga yang tinggi. Walaupun daerah ini terbilang makmur, tetapi kabupaten ini termasuk dalam kategori daerah tertinggal ditinjau dari fasilitas yang dimiliki daerah, keterbaruan teknologi, sumber daya manusia dan penghasilan rata-rata masyarakatnya. Image atau pandangan bahwa daerah ini adalah daerah makmur karena terdapat 6 perusahaan swasta besar tidak sepenuhnya benar, karena roda ekonomi dipegang oleh orang tertentu dengan modal besar dan perkebunannya yang 
sangat luas. Hal ini ditunjukkan lebih dari $20 \%$ masyarakatnya masih dikategorikan miskin.

Akar masalah sebenarnya yang mereka hadapi adalah minimnya pengetahuan dan ketrampilan untuk mengolah limbah organik perkebunan mereka berikut hasil sampingnya yang berjumlah sangat fantastis, menjadi sumber energi alternatif untuk mengatasi kelangkaan bahan bakar gas akibat pencabutan subsidi. Masalah selanjutnya adalah para petani di kabupaten tersebut belum bisa mengolah limbah hasil perkebunan mereka menjadi pupuk organik bernutrisi tinggi sehingga masih mengadalkan asupan pupuk dari pemerintah. Selain itu, karena keterbatasan sumber daya manusia maka para petani belum dapat mengolah hasil samping perkebunan mereka menjadi barang kerajinan yang bernilai ekonomis tinggi sehingga dapat menambah penghasilan rumah tangganya. Beberapa kali para kelompok tani berinisiatif untuk mencari narasumber yang kompeten untuk membantu memecahkan permasalahan mereka, namun karena keterbatasan kemampuan maka sampai saat ini belum tercapai keinginan tersebut.

Bertolak dari tersedianya limbah bahan organik berupa Tandan kosong kelapa sawit (TKKS) berikut cangkangnya, dan bonggol, kulit (klobot) beserta batang jagung dengan jumlah yang sangat melimpah maka Tim IbM FMIPA Universitas Bengkulu mencoba untuk membantu meningkatkan pengetahuan dan ketrampilan kepada para warga kelompok tani untuk mengolah limbah bahan organik yang dihasilkannya menggunakan teknologi fermentasi. Adapun akan dilakukan pelatihan produksi biogas sederhana skala rumah tangga dengan bahan dasar limbah organik perkebunan. Kemudian pelatihan pengolahan limbah produksi biogas berupa slurge yang dapat dimanfaatkan sebagai pupuk organik nutrisi tinggi dan pengolahan limbah organik lainnya menjadi kerajinan tangan dengan nilai ekonomis tinggi. Kegiatan ini dilakukan dengan harapan daerah ini dapat menjadi daerah mandiri dalam pemenuhan kebutuhan energi dan lahan pertaniannya saat ini dan berlanjut dimasa yang akan datang sehingga mengurangi kebergantungan beban energi dan bantuan pemerintah.

Biogas adalah campuran mudah terbakar gas Ini terutama terdiri dari methane $\left(\mathrm{CH}_{4}\right)$ Dan karbon dioksida $\left(\mathrm{CO}_{2}\right)$ dan terbentuk dengan bantuan bakteri anaerob. Gas yang terbentuk berasal dari respirasi decomposer/mikroorganisme dan komposisi gas tergantung pada substansi yang sedang membusuk. Komposisi terbesar dari biogas adalah metana 5570\% dan karbondioksida 30-45\% (Jogersen, 2009).

Sebuah biogas digester dasar terdiri dari sebuah tangki di mana bahan organik dicerna, dikombinasikan dengan sebuah sistem untuk mengumpulkan dan menyimpan biogas yang dihasilkan. Digester dapat cukup sederhana, dan rincian bervariasi tergantung pada bahan yang tersedia dan kebutuhan masyarakat. Saat biogas dihasilkan, tangki bagian dalam terisi dengan gas sehingga tangki naik. Jika biogas digunakan maka tangki penyimpanan gas bagian dalam tenggelam kembali ke dalam tangki yang lebih besar. Dalam sistem ini, tangki dalam bertindak baik sebagai penyimpanan dan sebagai penutup untuk tangki digester. Jarak antara dinding tangki cukup sempit untuk mencegah jumlah 
yang signifikan oksigen memasuki digester yang akan membunuh bakteri anaerob yang menghasilkan metana. Pada research center Tamera, untuk volume digester 3000 liter biasanya membutuhkan sekitar 40-60 liter biomassa setiap hari yang menghasilkan gas yang cukup selama beberapa jam untuk memasak setiap hari (Culhane et al, 2010).

Desa sumber makmur merupakan salah satu desa yang termasuk dalam kabupaten muko-muko, jauhnya jarak antara kabupaten ini dengan ibukota provinsi membuat harga kebutuhan sehari-hari menjadi sangat mahal, kenaikan harga bisa mencapai $30 \%$ dari harga normal. Sejak diterapkan pembatasan subsidi BBM di era pemerintahan baru, pemenuhan kebutuhan akan BBM menjadi semakin sulit di daerah ini, warga menjadi antri di SPBU, stok yang ada pun tidak mencukupi. Bahan bakar gas untuk keperluan rumah tangga sangat sulit di dapat, apalagi setelah pengapusan subsidi untuk bahan bakar gas, harga LPG setiap bulan terus merangkak naik menyesuaikan fluktuasi harga minyak dunia. Banyak warga yang beralih menggunakan kayu bakar untuk memasak dengan memanfaatkan pelepah sawit ataupun Tandan Kosong Kelapa Sawit (TKKS) dan cangkang sisa penggilingan sawit yang dibuang berserakan oleh 6 pabrik pengolahan kelapa sawit. Dikarenakan jumlahnya sangat banyak dan semakin menumpuk, maka menjadi limbah yang menimbukan bau sangat tidak sedap dan mengganggu keindahan lingkungan. Sama halnya dengan para petani jagung, mereka hanya memanfaatkan pipilan jagung keringnya saja, sedangkan tongkol, kulit dan batangnya hanya dibakar atau dibuang dengan percuma. Total limbah bahan organik yang dihasilkan dari sektor perkebunan tersebut mencapai \pm 67.000 ton/pertahun, jumlah yang sangat fantastis.

Permasalahan selanjutnya adalah, para petani dan warga sekitar belum mampu mengolah limbah sampah organik menjadi sumber energi alternatif selain minyak bumi dan pengolahan hasil sampingnya, sehingga mereka masih mengandalkan energi fosil sebagai sumber energi utama dan bergantung pada pasokan pupuk subsidi pemerintah untuk pemenuhan kebutuhan perkebunan mereka walaupun dengan harga yang sangat mahal. Dengan sedikit implementasi IPTEKS terapan maka kelangkaan bahan bakar gas dan pupuk subsidi di daerah ini dapat teratasi dengan memanfaatkan limbah organik yang mereka hasilkan dari perkebunan mereka sendiri.

Tujuan pelaksanaan program IbM ini adalah: (a) meningkatkan pengetahuan dan keterampilan masyarakat tentang pengolahan limbah kelapa sawit dan jagung menjadi energi alternatif dengan pendekatan IPTEKS terapan, (b) melatih pengolahan limbah kelapa sawit dan jagung sebagai energi alternatif dengan pendekatan IPTEKS terapan, (c) mendampingi cara pengolahan, pembuatan dan pemasaran produk limbah sawit dan jagung dalam skala industri rumah tangga. Adapun target khusus dari kegiatan ini adalah masyarakat mampu mengolah limbah kelapa sawit dan jagung untuk di proses menjadi biogas dan briket arang serta memanfaatkan hasil sampingnya sebagai pupuk organik dan berbagai kerajinan tangan yang bernilai ekonomis tinggi. 


\section{METODE PENGABDIAN}

\section{Lokasi dan waktu}

Lokasi kegiatan ini adalah di desa Sumber makmur kabupaten Muko-muko, kegiatan pengabdian dimulai pada bulan Maret sampai dengan Nopember 2016.

\section{Alat dan bahan}

Alat

Tandon air $2000 \mathrm{~L}$ dan $750 \mathrm{~L}$, pipa PVC 1,2 dan 4,4 incfi, pipa besi 0,5 inchi, selang fiber, plastik dan karet, konektor T dan L, barometer, kran gas, bak plastik besar, kenur, plastik steel, amplas, meteran dan kelengkapannya, barometer, selang karet, lem uhu, gunting, pemutih, pewarna, benang, jarum jahit dan paku.

\section{Bahan}

Limbah kelapa sawit berupa TKKS (tandan kosong kelapa sawit), cangkang kelapa sawit, kulit, batang dan bonggol jagung, $\mathrm{EM}_{4}$, tepung tapioka, semen, kerikil, pasir, kertas karton, pita berwarna, lampu dan kayu balok.

\section{Cara kerja}

Pembuatan instalasi biogas, pupuk organik cair dan padat (Bahrin dkk, 2011)

1. Pasang peralatan digester dengan skema seperti di bawah ini : (Care, 2009)

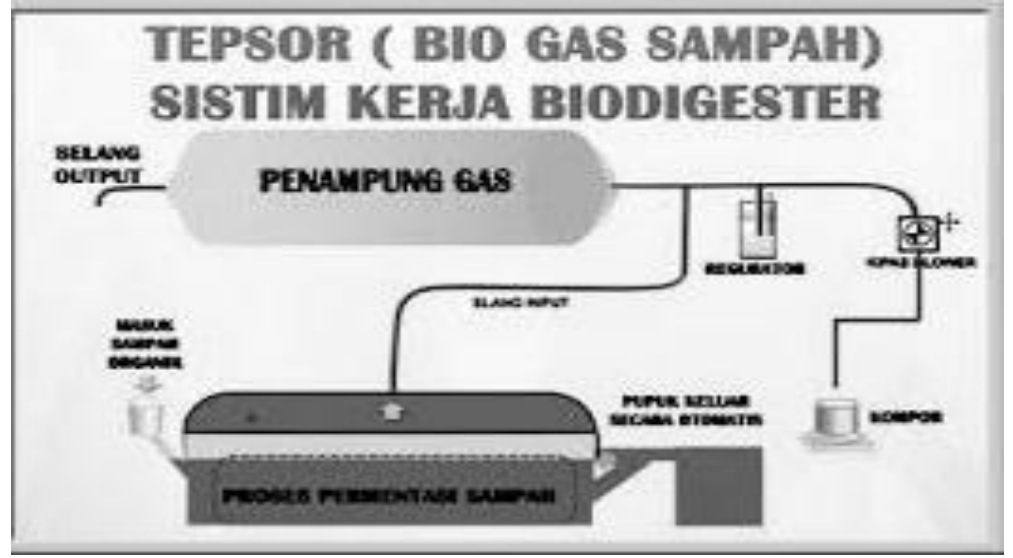

2. Masukkan bahan untuk membuat biogas ke dalam reaktor lewat tempat pengisian, beri $\mathrm{EM}_{4}$ sesuai takaran yang tersedia, setelah itu akan berjalan sistem produksi biogas didalam reaktor.

3. Sesudah lebih kurang 10 hari reaktor biogas serta penampung biogas bakal tampak mengembung serta mengeras lantaran ada biogas yang dihasilkan. Biogas telah bisa dipakai untuk bahan bakar.

4. Sekali-sekali reaktor biogas digoyangkan agar berlangsung penguraian yang prima serta gas yang terbentuk dibagian bawah naik ke atas, kerjakan juga pada tiap-tiap pengisian reaktor. Pengisian bahan biogas setelah itu bisa dikerjakan tiap-tiap hari, 
yakni sejumlah $+40 \mathrm{~kg}$ tiap pagi serta sore hari. Bekas pemrosesan bahan biogas berbentuk sludge (lumpur) akan keluar dari reaktor setiap saat dikerjakan pengisian bahan biogas. Bekas hasil pemrosesan bahan biogas itu dipakai segera untuk pupuk organik, terbaik dalam situasi basah ataupun kering. Sludge kemudian di pisahkan antara padatan dan airnya, bagian padat dijadikan pupuk organik padat sedangkan airnya menjadi pupuk organik cair yang kaya nutrisi.

\section{Pembuatan briket arang cangkang kelapa sawit}

Bahan berupa limbah cangkang sawit dan batang jagung dimasukkan dalam tungku pembakaran (kaleng roti bekas) selama lebih dari 2 jam hingga material menjadi arang. Arang dikeluarkan dan biarkan beberapa saat agar panas mereda, kemudian ditumbuk hingga halus dan diayak. Panaskan tepung tapioka hingga menjadi bubur lem, campurkan arang halus dengan bubur lem tepung tapioka dengan perbandingan ideal $1 \mathrm{~kg}$ bubur tapioka dengan $10 \mathrm{~kg}$ arang halus. Adukan dimasukkan ke dalam cetakan paralon, briket basah dikeringkan dengan menjemurnya di bawah sinar matahari. Setelah kering briket disimpan dan siap untuk digunakan.

\section{Pembuatan kerajinan tangan kulit dan bonggol jagung \\ Persiapan material bahan baku kerajinan}

Dipilih kulit jagung yang kondisinya baik, kemudian kulit jagung dilepaskan satu persatu dan dipilah sesuai lembarannya. Lembaran daun pertama hingga daun ketiga dipisah karena lembaran tersebut merupakan kualitas yang baik. Jika ingin diwarnai kulit jagung yang sudah dipilah selanjutnya direndam dalam pemutih supaya hilang warna dasarnya, lalu direbus dengan pewarna atau wantek dan direbus selama satu jam dan dibolak-balik agar warnanya merata. Kulit jagung kemudian ditiriskan dan dikeringkan, jangan dijemur diterik matahari karena kulit jagung nanti menjadi pecah. Kulit jagung yang telah kering selanjutnya disetrika dengan suhu sedang, lalu dilapis menjadi dua sebelum dipola. Setelah itu gunting sesuai dengan pola dan ditempelkan pada kertas kaku yang dipotong dengan pola yang sama. Hias sesuai keinginan dan jadilah produk kerajinan tangannya.

\section{Pembuatan keranjang serbaguna}

Kulit jagung yang telah kering dibuat menjadi tambang dengan cara dipelintir, kemudian anyam secara berselang-seling dengan model sesuai keinginan. Jahit dan lem dibagian ujung, dapat ditambahkan pita sebagai pemanis.

\section{Pembuatan kap lampu}

Potong tongkol jagung bulat-bulat, satukan bagian ujung dengan menggunakan lem dg terlebih dahulu disusun pada pola kap lampu yg terbuat dari paralon atau katon. Susun mulai dari bawah sampai ke bagian atas sesuai model yang dibuat. Setelah lem kering, 
lepaskan dari pola, kemudian letakkan pada dudukan lampu yang telah dibuat dan dilengkapi dengan lampu dan kabelnya.

\section{Pembuatan tas berbahan dasar kulit jagung.}

Kulit jagung yang telah kering, disetrika dan diwarnai, dianyam selang seling seperti menganyam tikar. Kemudian lapisi bagian dalamnya dengan kain dengan warna senada dan gunting sesuai dengan pola. Satukan kedua sisi dan jahit, beli resleting dan tali jika diperlukan.

\section{Khalayak sasaran}

Khalayak sasaran ini adalah kelompok tani sawit dan petani jagung yang merupakan mitra dari kegiatan. Dua kelompok ini merupakan masyarakat yang berhubungan langsung dengan material/bahan yang diolah (limbah TKKS, cangkang sawit dan limbah jagng) dan langsung dapat memanfaatkan hasil kegiatan pengabdian.

\section{HASIL DAN PEMBAHASAN}

Kegiatan pengabdian masyarakat telah dilakukan di daerah muko-muko yang merupakan sentra perkebunan di bengkulu. Pendekatan yang dilakukan bersifat "Bottom up", dimana perencanaan tindakan diupayakan menjawab permasalahan dan kebutuhan Kelompok Tani dilakukan secara partisipatif. Tahapan yang dilakukan secara umum adalah sebagai berikut :

\section{Identifikasi potensi}

Pelaksana bersama Kelompok Tani mengidentifikasi potensi yang dimiliki, yaitu keahlian anggota kelompok tani, limbah TKKS dan jagung sebagai bahan baku biogas, peralatan, kondisi ekonomi, pangsa pasar produk kerajinan serta lingkungan eksternal yang terkait kegiatan pengabdian.

\section{Analisis kebutuhan}

Menganalisis kebutuhan Kelompok Tani untuk mencari solusi dari permasalahan. Memprioritaskan kebutuhan Kelompok Tani yang paling mendesak disesuaikan dengan kemampuan Kelompok Tani.

\section{Rencana kerja}

Setelah menganalisis kebutuhan Kelompok Tani, pelaksana membuat rencana kerja atau kegiatan yang akan diterapkan. Rencana kerja meliputi persiapan, pelaksanaan dan evaluasi kegiatan 


\section{Pelatihan}

Pelatihan meliputi (1) pembuatan instalasi biogas limbah kelapa sawit dan jagung, (2) pelatihan pembuatan pupuk organik cair dan padat kaya nutrisi hasil samping produksi biogas, (3) pembuatan briket arang kelapa sawit, dan (4) pelatihan dan demosntrasi pembuatan kerajinan tangan limbah kulit dan tongkol jagung.

\section{Monitoring dan evaluasi untuk semua program kegiatan dan mengevaluasinya sesuai target luaran.}

Evaluasi keberhasilan kegiatan ini dilakukan melalui :

\section{a. Relevan (relevance)}

Ada kesesuaian antara misi program dan sumberdaya yang tersedia. Kegiatan ini bertujuan untuk memberdayakan sumber daya yang ada, dimana limbah TKKS dan jagung tersedia secara melimpah di daerah ini.

\section{b. Efisiensi dan produktivitas (efficiency and productivity)}

Kegiatan yang dilakukan berdampak pada peningkatan pendapatan petani dan atau peserta pelatihan dengan adanya energi alternatif bersumber dari limbah lingkungan mereka. Setelah dilakukan kegiatan ini, minimal mereka dapat menggantikan sebagian sumber energi bahan bakar fosil yang selama ini diandalkan oleh mereka.

\section{c. Keberlanjutan (sustainability)}

Kegiatan yang dilakukan dapat dilaksanakan secara berkelanjutan, sampai dengan saat ini instalasi biogas masih digunakan, pupuk padat dan juga cair dihasilkan dari instalasi tersebut. Oleh karena itu, ketergantungan mereka terhadap pupuk sintetis berharga mahal dapat tergantikan oleh pupuk alami, sebagian sumber energi fosil juga tersubstitusi oleh biogas.

\section{d. Luas cakupan (scope of implementation)}

Sejauh mana kegiatan ini dapat diadopsi oleh peserta pelatihan? Berdasarkan hasil kegiatan bahwa teknologi yang diterapkan dalam kegiatan pengabdian ini dapat diadopsi oleh kelompok petani yang merupakan kelompok penghasil limbah utama berupa TKKS dari hasil perkebunan mereka. Namun dalam hal ini terdapat kendala dalam hal kemampuan membuat instalasi biogas secara mandiri, dan .kurangnya minat pembuatan kerajinan tangan limbah jagung beserta pemasarannya.

\section{KESIMPULAN DAN SARAN}

\section{Kesimpulan}

(a) Masyarakat kelompok tani sawit telah mampu membuat instalasi biogas beserta memperoleh manfaat hasil sampingnya berupa pupuk cair dan pupuk padat yang berasal dari limbah biogas, selain itu mereka telah dapat mengolah cangkang sawit menjadi briket arang yang dapat dipergunakan untuk memasak.

(b) Ibu-ibu kelompok petani jagung dapat mengolah limbah jagung menjadi kerajinan tangan yang bernilai ekonomis. 


\section{Saran}

(a) Diperlukan dorongan yang kuat dari pihak luar agar para petani tersebut dapat keluar dari main set pemikiran yang berorientasi penuh terhadap ketergantungannya pada perkebunan sawit. Hal ini dikarenakan pemegang kekuatan ekonomi di sana dipegang oleh para cukong yang mempunyai lahan perkebunan yang sangat luas, sedangkan warga hanya menjadi buruh atau sekalipun memiliki lahan maka sangat terbatas luasnya.

(b) Masyarakat memerlukan pendampingan terus menerus terhadap kegiatan pengabdian yang telah dilakukan, ada yang sudah mandiri namun ada pula yang mesti selalu diingatkan mengenai prosedur fermentasi.

\section{DAFTAR PUSTAKA}

Asian Biomass Handbook, 2014, Manfaat Biomassa.

Bahrin, D., Anggraini, D., dan Pertiwi, M.B., 2011, Pengaruh Jenis Sampah, Komposisi Masukan dan Waktu Tinggal terhadap Komposisi Biogas dari Sampah Organik Pasar di Kota Palembang, Prosiding Seminar AvoER ke-3, Palembang.

BPS Bengkulu, 2011, Luas Panen dan Produksi Jagung Menurut Kabupaten/Kota di Bengkulu.

BPS Mukomuko, 2014, Luas Panen dan Produksi Menurut Jenis Komoditas di Kabupaten Mukomuko.

Care, K., 2009, Cara Membuat Digester Biogas, Komunitas Mahasiswa Sentra Energi, Kamase.

Culhane T.H., Tamera, Village, S., Marazzi V-ARCò, 2010, Biogas Digester, Tamera Peace Research Center, Monte Cerro.

Djalil, R., 2015, Potensi Kabupaten Mukomuko, P2KP Mukomuko.

Elykurniati, 2011, Pemanfaatan Limbah Padat Cangkang Kelapa Sawit untuk Pembuatan Pupuk Cair Kalsium Sulfat, Laporan Penelitian.

Hogantara, F.R., 2015, Efektifitas Mikroorganisme EM4, Pustaka Jakarta.

Jørgense, P.T., 2009, Biogass-Green Energy, Faculty of Agricultural Sciences, Aarhus University.

Lukum, H., Isa, K., Sihaloho, M., 2012, Pemanfaatan Arang Briket Limbah Tongkol Jagung Sebagai Bahan Bakar Alternatif.

Mujahidah, Mappiratu, Sikanna, R., 2013, Kajian Teknologi Produksi Biogas dari Sampah Basah Rumah Tangga, Online Jurnal of Natural Science, Vol. 2 (1): 25-34.

Natalie, M., dan Nugrahini, P., 2014, Pengolahan Sampah Organik (Sayur-Sayuran) Pasar Tugu menjadi Biogas dengan Menggunakan Starter Kotoran Sapi dan Pengaruh Penambahan Urea Secara Anaerobik pada Reaktor Batch, SNTMUT-2014.

Pecawan, Y., 2015, Minim Subsidi, Petani Mukomuko Kekurangan Pupuk 10 Ribu Ton per Tahun. Antara News.

Sejahtera, I.M., 2015, Biogas Bagian I, Indah Multifarm Sejahtera, Jakarta. 
Triastuti, R., Rohmad, Z., Rahayu, Zulaekha, S., dan Nugrogo, D., 2013, IbM Kelompok Usaha Bersama Payet Di Karanganyar, Laporan kegiatan IbM.

\section{FOTO KEGIATAN}
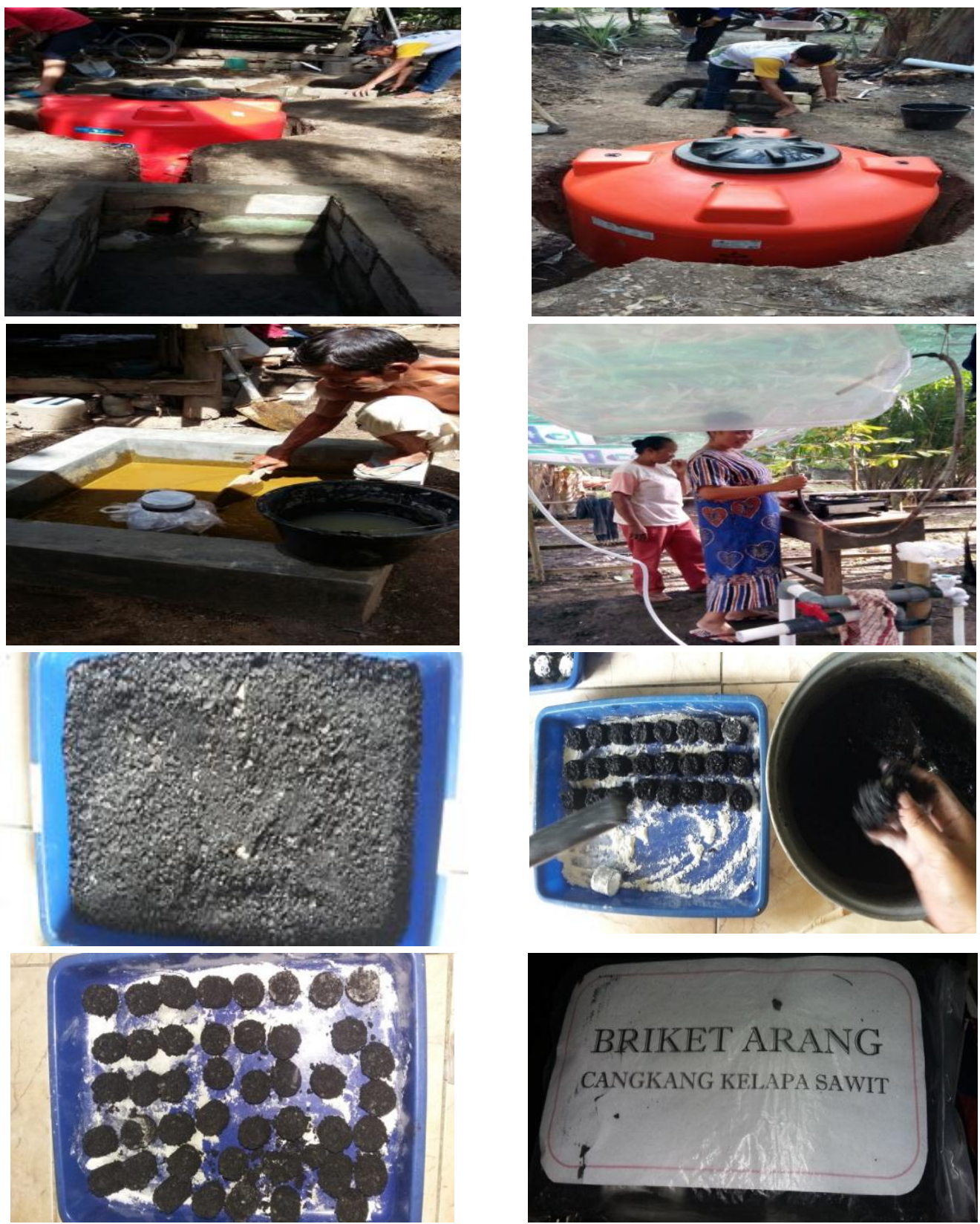

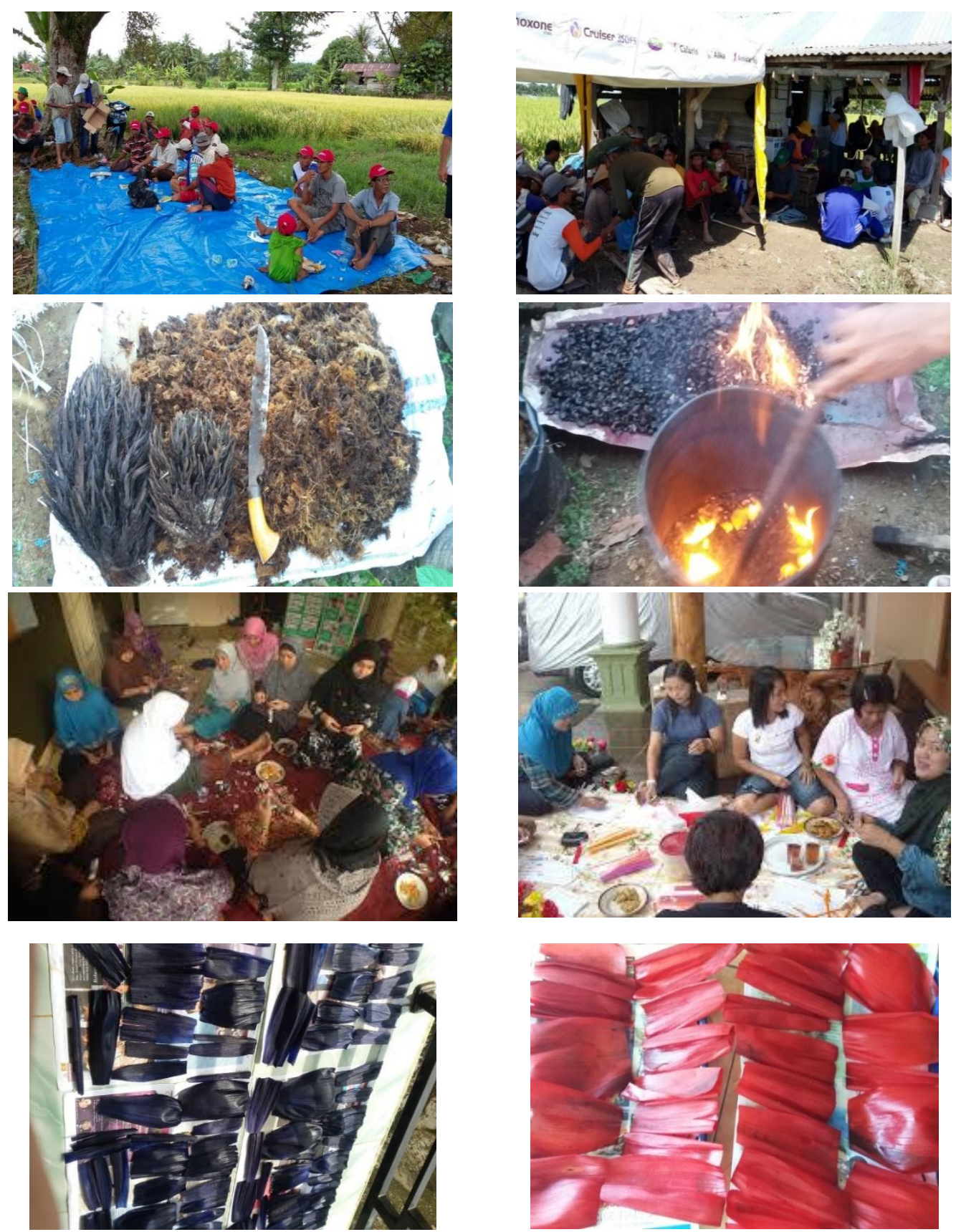